\title{
Widespread parallel population adaptation to climate variation across a radiation: implications for adaptation to climate change
}

\author{
ROGER S. THORPE, ${ }^{*}$ AXEL BARLOW ${ }^{* 1}$ ANITA MALHOTRA* and YANN SURGET-GROBA* $\dagger$ \\ *School of Biological Sciences, Bangor University, ECW Building, Bangor Gwynedd LL57 2UW, UK, †Institut des Sciences de \\ la Forêt Tempérée, Université du Québec en Outaouais, 58 rue Principale, Ripon, QC J0V 1V0, Canada
}

\begin{abstract}
Global warming will impact species in a number of ways, and it is important to know the extent to which natural populations can adapt to anthropogenic climate change by natural selection. Parallel microevolution within separate species can demonstrate natural selection, but several studies of homoplasy have not yet revealed examples of widespread parallel evolution in a generic radiation. Taking into account primary phylogeographic divisions, we investigate numerous quantitative traits (size, shape, scalation, colour pattern and hue) in anole radiations from the mountainous Lesser Antillean islands. Adaptation to climatic differences can lead to very pronounced differences between spatially close populations with all studied traits showing some evidence of parallel evolution. Traits from shape, scalation, pattern and hue (particularly the latter) show widespread evolutionary parallels within these species in response to altitudinal climate variation greater than extreme anthropogenic climate change predicted for 2080. This gives strong evidence of the ability to adapt to climate variation by natural selection throughout this radiation. As anoles can evolve very rapidly, it suggests anthropogenic climate change is likely to be less of a conservation threat than other factors, such as habitat loss and invasive species, in this, Lesser Antillean, biodiversity hot spot.
\end{abstract}

Keywords: Anolis, biodiversity conservation, climate change, island archipelagos, natural selection, parallel evolution, phylogeography

Received 2 August 2014; revision received 20 January 2015; accepted 21 January 2015

\section{Introduction}

Deterministic convergent macroevolution in radiations (Mahler et al. 2013) and parallel microevolution within separate species are important because they can reveal the nature of the ecological and evolutionary forces involved (Nosil et al. 2002). Where several populations or taxa show parallel or convergent adaptation in response to common ecological factors, this can be a potent argument for natural selection (Arendt \&

Correspondence: Roger S. Thorpe, Fax: +44 1248 382569;

E-mail: r.s.thorpe@bangor.ac.uk

${ }^{1}$ Present Address: Institute for Biochemistry and Biology, University of Potsdam, Karl-Liebknecht-Str. 24-25, 14476 Potsdam (Golm), Germany
Reznick 2008; Wake et al. 2011). Parallel genotypic adaptation was thought to be rare, but several instances from a wide range of organisms are known (Wood et al. 2005), including several populations within the same species (Schat et al. 1996; Colosimo et al. 2005). Nevertheless, several studies of homoplasy have not yet revealed cases of universal, or widespread, occurrence of parallel geographic variation across a comprehensively studied generic radiation (Wood et al. 2005; Arendt \& Reznick 2008; Wake et al. 2011).

It is important to know whether natural populations can adapt to anthropogenic climate change by natural selection (Quintero \& Wiens 2012). The consensus is that they cannot (Barnosky et al. 2011; Bellard et al. 2012; Quintero \& Wiens 2012), but rigorous population level studies may show such adaptation (Pespeni et al. 
2013). Parallel microevolution within separate species can demonstrate natural selection (Arendt \& Reznick 2008; Wake et al. 2011), including natural selection to climate variation (Brown et al. 1991). In this study, we used a broad spectrum of quantitative traits (QTs) across a radiation in order to test the evidence for parallel natural selection and to give insights into the impact of anthropogenic climate change.

The mountainous islands in the Lesser Antillean arc, a biodiversity hot spot (Myers et al. 2000), are each inhabited by one or two species of small arboreal lizards of the genus Anolis which occupy most of the habitats within each island (Fig. 1). Within each island (Figs 1 and 2), a pronounced climatic zonation is observed with coastal localities in the rain shadow being hot, xeric and seasonal while the inland montane rainforests are cooler, wetter and less seasonal. This climatic variation is associated with pronounced intraspecific geographic variation in a broad spectrum of QTs, from size, shape, hue and pattern to scalation, the most apparent being hue and pattern (Fig. 1).

Quantitative traits may be influenced by both genetic factors and plasticity. While the impact of plasticity on traits such as anole leg length can be demonstrated (Kolbe \& Losos 2005; Losos 2009), broad sense heritability studies of anole QTs clearly show that there is a strong heritable component (Calsbeek et al. 2006; Calsbeek \& Bonneaud 2007; Calsbeek \& Smith 2007; Losos 2009; Eales et al. 2010). Moreover, a common garden study focussed specifically on the altitudinal climatic variation of the QTs of a Lesser Antillean Anole (A. oculatus) showed clearly that the geographic variation in these traits was not primarily due to plasticity (Thorpe et al. 2005). Finally, an anole secondary contact zone in north-east Martinique shows marked trait differences either side of the zone even though the climate is broadly similar as measured by the 19 Worlclim climatic variables used in this study (Thorpe et al. 2012). This cannot be explained by simple plasticity, but is compatible with genetic control.

Overall, the geographic variation in QTs in Lesser Antillean anoles does not associate with mtDNA phylogeographic lineage, but overwhelmingly relates to natural selection for current environmental conditions. Evidence comes from natural selection experiments (Malhotra \& Thorpe 1991; Thorpe et al. 2005), numerous correlative studies between habitat and QT spatial patterns (references in Thorpe et al. 2005 and Appendix S1, Supporting information), and rapid adaptation of invasive species (Eales et al. 2010). Given that these main islands were never joined above sea level in the past (Martin-Kaye 1969), overwater dispersal of anoles would be required for interisland colonization. Colonization, and the subsequent range expansion from xeric coastal to montane conditions inland, would expose each species to a wide range of climatic conditions of a greater magnitude than that predicted from anthropogenic climate change (Fig. 2). Hence, the numerous independent Lesser Antillean anole species provide a powerful test of parallel evolution in geographic variation that adapts populations to climatic variation. This study attempts to test for this parallel evolution at the intraspecific level across the Anolis roquet (southern islands) and bimaculatus (northern islands) Series (Fig. 1) where they occur on the larger mountainous islands (Fig. 1), using a broad spectrum of 18 traits from five character systems [the Anolis genus is very speciose, and anole workers recognize the main lineages as 'Series' (Losos 2009)].

We demonstrate widespread evolutionary parallels within these species in response to altitudinal climate variation that is greater than the more extreme predictions of temporal anthropogenic climate change. This gives strong evidence of the ability to adapt to climate variation by natural selection throughout this radiation, and as there is substantial evidence that anoles can evolve very rapidly, it suggests anthropogenic climate change is likely to be less of a conservation threat than other factors in these biodiversity hot spots.

\section{Methods}

\section{Data sets}

Anoles from mountainous Lesser Antillean islands were sampled: Anolis marmoratus, A. oculatus (bimaculatus Series) and NW Martinique $A$. roquet, central Martinique A. roquet, A. luciae, A. trinitatis, $A$. aeneus and $A$. richardii (roquet Series) using eight sets of data. The north-west and central Martinique lineages from distinct precursor islands (Thorpe et al. 2010) are treated as allospecies (Fig. 1 and Appendix S1, Supporting information). The

Fig. 1 Map of the mountainous Lesser Antilles showing sample localities for the main data sets and the primary phylogeographic regions within each island. The bimaculatus Series are north, and the roquet Series south, of the blue bar. Numbered green circles are montane sites, numbered red circles are xeric sites, and un-numbered black circles are additional sites used in analyses of climate and phylogeography. The black lines within an island are the well-supported primary phylogeographic dichotomy. Details of the Martinique sites for both data sets C and D are in Appendix S1, Supporting information. The thumbnail images are examples of males from xeric and rainforest habitats of each species (locality identity and comprehensive images of both sexes in Fig. S2, Supporting information). 


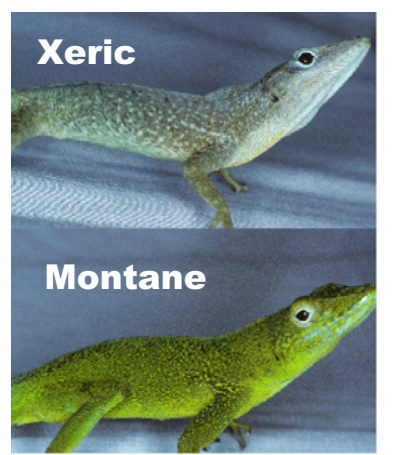

Basse Terre marmoratus

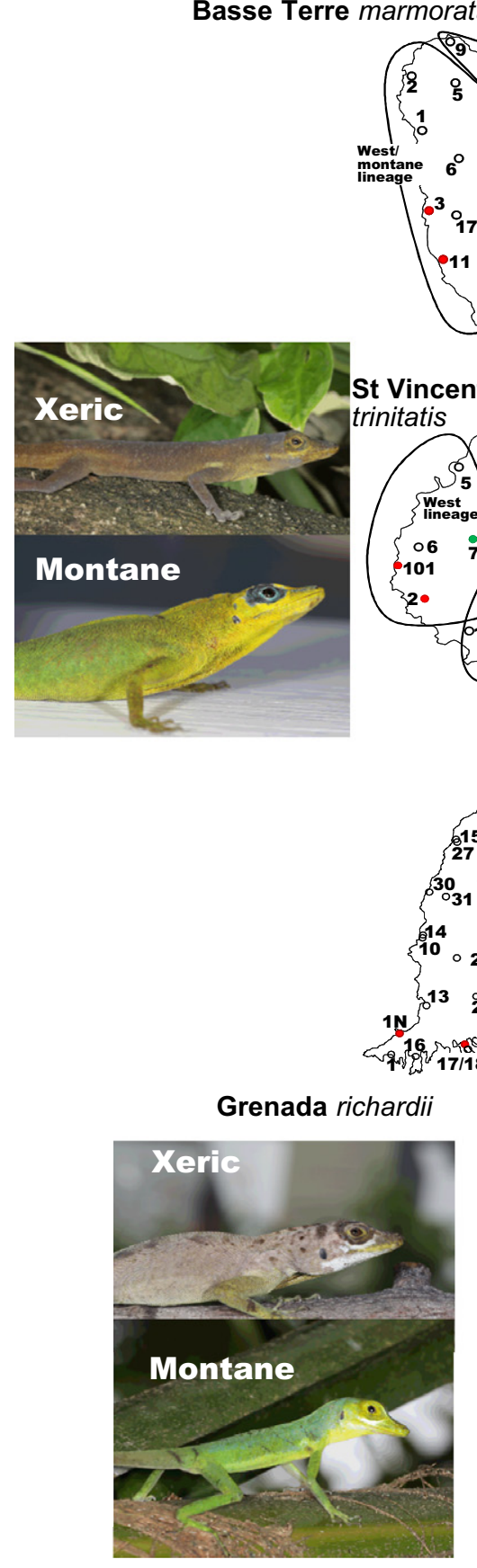

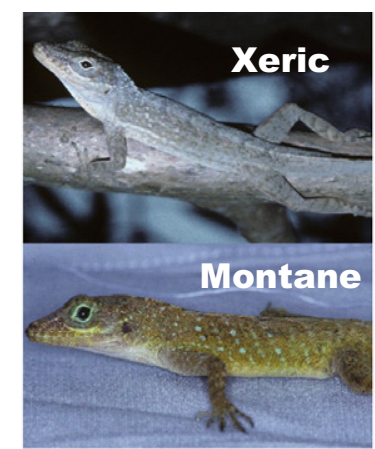

\section{Dominica oculatus}

3020

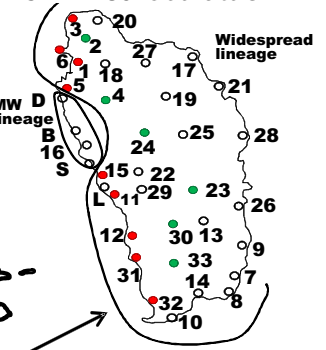

$\pi$

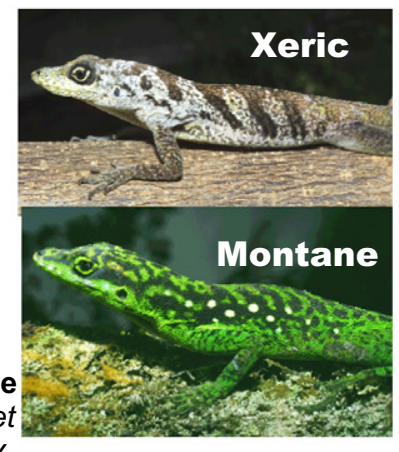

NW roquet
gomplex

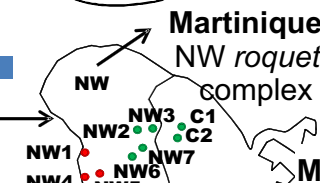

Martinique

¿ Central

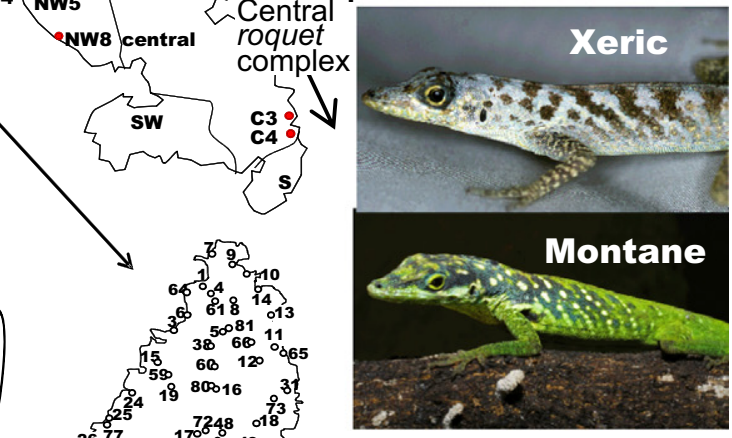

$2677 \quad 17^{7248} \quad 018^{\circ}$

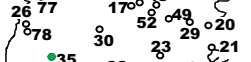

$34 \quad 35 \quad 32 \quad 5 t_{0}^{221}$

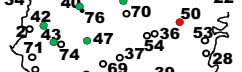

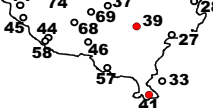

St Lucia luciae
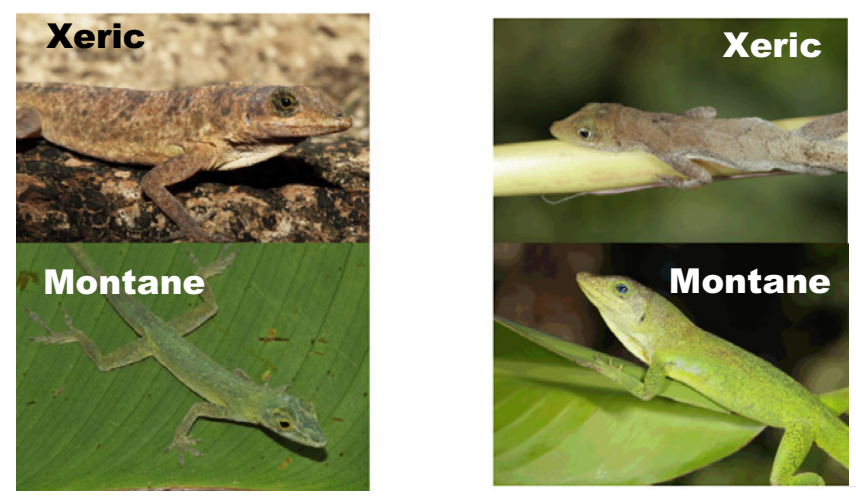


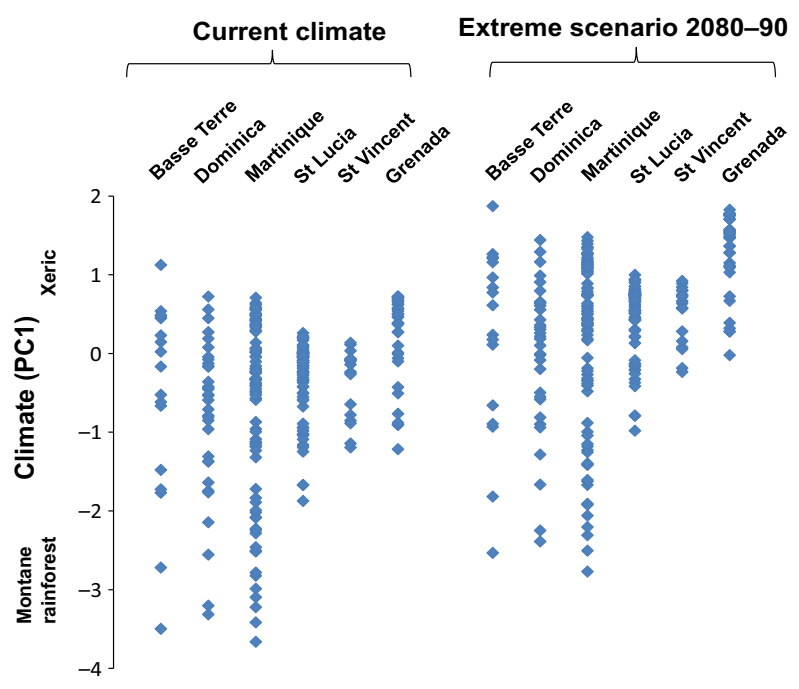

Fig. 2 Current and predicted climate for each site from each of the mountainous Lesser Antilles. The first principal component from an analysis of 19 WorldClim climate variables computed across all sites on all islands for both current and extremecase-scenario predictions for 2080-90 after anthropogenic climate change.

following QTs were analysed: snout-vent length, jaw length, head length, depth and width, upper and lower leg length, hind-foot fourth toe length and lamellae number, dewlap size (with body proportions regressed against snout-vent length), chevron intensity, the relative proportions of red, green and blue hues in the colour of the dorsum, achromaticity (grey trunk) measured as equality of RGB proportions, number of ventral and dorsal scales along the trunk length, and number of circum-trunk scales. Not all traits could be recorded from all data sets. Details of the data sets, including trait definition, are given Appendix S1, Supporting information and references therein. Some comparisons are also made with the invasive A. cristatellus (Eales et al. 2010) on Dominica and the dry island species $A$. bonairensis from Bonaire and A. blanquillanus from Blanquilla.

\section{Current climate and replicated xeric and montane rainforest sites}

The selection of replicated xeric and montane rainforest sites (Fig. 1) was informed primarily by climate data and secondarily, where appropriate, by mtDNA gene trees. Across each island, the climate data were summarized by a principal component analysis (PCA) of 19 $\log _{\mathrm{e}}$-transformed variables downloaded at 30 arc-second resolution from the WorldClim website (www.worldc lim.org). Principal components were extracted from a pooled within-group variance-covariance matrix (Thorpe 1988), where each island is a group and each site a case. This procedure optimizes the ordination of within-island climate differences among sites. All sites in Fig S1, Supporting information and all Martinique transects sites (Thorpe et al. 2010; Surget-Groba et al. 2012) are included. Replicated extreme xeric and montane sites based on PC1 were selected for contrast where available.

Numerous studies (referenced in Thorpe et al. 2005) show that intraspecific lineages in Lesser Antillean anoles are not generally associated with QT differentiation. Some species lack a well-resolved phylogeographic structure, and even in those that have deep, well-supported, phylogenetic divisions may overlap geographically (Thorpe et al. 2010). Moreover, where microsatellite data are available, such as A. oculatus from Dominica (Stenson et al. 2002), the A. roquet complex from Martinique (Thorpe et al. 2010) and A. luciae from St. Lucia (Y. Surget-Groba, pers. comm.), these phylogeographic lineages are not genetically isolated entities. Consequently, intraspecific lineage is only a secondary criterion for selecting sites. Nevertheless, in species where the primary intraspecific mtDNA split is well supported, sites were selected from just one phylogeographic area.

\section{Molecular and phylogenetic methods}

To infer intraspecific phylogeographic structure, a combination of database and novel mitochondrial DNA sequences was used. These provided dense geographic sampling of the complete island distributions of each species investigated and, often, multiple individuals from each sampled locality (Fig. 1). The mitochondrial cytochrome $\mathrm{b}$ gene (MT-CYB) was used as a marker for all species, with the mitochondrial cytochrome oxidase subunit 1 gene (MT-CO1) added for A. aeneus. Previous studies have shown that these markers can provide a high level of variability and resolution between phylogeographic lineages in these species which can be linked in detail and depth to the geography and timing of geological events (Thorpe et al. 2008, 2010; Surget-Groba \& Thorpe 2013).

Novel DNA sequences were generated by extracting total DNA from anole tail tips (readily autotomized). Mitochondrial fragments were then PCR-amplified using the primers MTA-S (5'-ATCTCAGCATGATGAA ACTTCG-3') and MTF-S (5'-TTTGGTTTACAAGACCA ATG-3') as in Thorpe et al. (2008) for MT-CYB, and LCO1490 (5'- GGTCAACAAATCATAAAGATATTG G-3') and HCO2198 (5'- TAAACTTCAGGGTGACCAA AAAATCA-3') for MT-CO1 (Folmer et al. 1994). Relationships among DNA sequences for all species were estimated using the Bayesian approaches in BEAST 1.7.4 (Drummond et al. 2012). Gene sequences were 
partitioned into first, second and third codon positions and separate, unlinked substitution models specified for each. JMODELTEST (Guindon \& Gascuel 2003; Posada 2008) was used to select optimal substitution models according to the corrected Akaike's information criterion. A range of model-testing procedures were carried out to determine the most appropriate molecular clock, population growth and substitution models for each sequence alignment. Poorly resolved gene trees (A. luciae and A. richardii) were compared to trees generated using an alternative Bayesian approach in MRBAYES 3 (Ronquist \& Huelsenbeck 2003). Further details of the molecular and phylogenetic methods, including details of model selection and the MCMC analyses, are provided in Appendix S1, Supporting information.

The resulting phylogenetic trees were used to identify a well-supported primary phylogeographic dichotomy within each species, which together with detailed transect data for modal lineage in the north-west and central Martinique 'allospecies' of the A. roquet complex (Thorpe et al. 2010), informed site selection.

\section{Comparison of current and predicted climate}

Current climatic data for all sites on all islands (19 bioclimatic variables) were downloaded from the WorldClim website as above. Equivalent bioclimatic data were also obtained for predicted future climates (MIROC 3.2 global climate model; Period 2080-2089) under emission scenario A2, from the Research Program on Climate Change, Agriculture and Food Security (CCAFS) data portal (www.ccafs-climate.org/data). Emission scenario A2 describes a world with regionally orientated economic development and continuous population growth (Nakicenovic \& Swart 2000) and is among the more extreme projections of anthropogenic climate change, predicting an increase in global average surface temperature of $3.4{ }^{\circ} \mathrm{C}$ by the period $2090-2099$, relative to 1980-1999 (Solomon et al. 2007). The $\log _{\mathrm{e}}$-transformed bioclimatic variables were subject to PCA (covariance matrix) with data included across all sites and both current and predicted climates. This optimizes the ordination of climate differences irrespective of time or geography.

\section{Comparison of xeric and montane data sets}

Two series of analyses were carried out. The first series of analyses were species-by-species analyses to establish significance and direction of character state differences between a trait in xeric-versus-montane habitats. Contrast ANOVAs with a QT as the variable, site as the group and individual specimens as the cases were carried out.
Contrast ANOvAs allow custom hypotheses to be tested where there are several categories (xeric and montane in this study), and at least one category has multiple groups (in this study each habitat has at least two sites) (Seltman 2014). There does not have to be an equal number of groups (sites) for each category. For each trait for each species, xeric and montane sets (Fig. 1) were compared by two-way contrast (both sexes) and one-way contrast (each sex) ANOVAs, expressing montane-xeric divergence for each QT in units of pooled within-site standard deviations. Parallel evolution of a trait between species is indicated by a set of species showing significant difference among contrast pairs in the same direction. Second, we tested for pervasive parallel evolution between habitat types by a two-way ANOVA on male site means with species and habitat type as factors, the latter factor being of key interest (the groups are habitat type for each species, and the cases are site means). In this study of intraspecific trends, the phylogenetic relationships among the species are not relevant.

\section{Results}

The climate difference between islands is trivial compared to the dominating factor, which is the withinisland difference between xeric and montane rainforest climates (Fig. 2). Similarly, while all islands show a difference in climate between current and extreme 2080 predictions, it is small compared to contemporary within-island differences (Fig. 2). The xeric/montane ordination is maintained in the predicted 2080 climate.

The BEAST reconstructions generally gave wellresolved trees for these densely sampled intraspecific studies. Where this is the case, the primary phylogeographic dichotomy for each species is represented in Fig. 1 with the sites and gene trees in Fig. 3. There is a western phylogeographic lineage for A. marmoratus in Basse Terre. Within this phylogeographic region, two xeric sites $(3,11)$ are compared to two montane sites $(7,8)$, Fig. 3a. There is restricted mid-west, and a widespread, phylogeographic region for A. oculatus in Dominica with nine xeric sites $(1,3,5,6,11,12,15,31,32)$ and six montane sites $(2,4,23,24,30,33)$ from the latter, Fig $3 b$. There are overlapping eastern and western phylogeographic regions for A. trinitatis in St Vincent with two xeric $(2,101)$ and two montane $(1,7)$ sites from the latter, Fig. $3 \mathrm{~d}$. There are overlapping northern and southern phylogeographic regions for $A$. aeneus in Grenada with two xeric (1N and 17/18/19/39 - these being one extended site) and two montane ( $2 / 7$ these being one extended site and 22) sites from the latter, Fig. 3e. For A. roquet from NW Martinique, there are four xeric sites (NW1, 4, 5, 8) and four montane sites 
1024 R. S. THORPE ET AL.

(A)

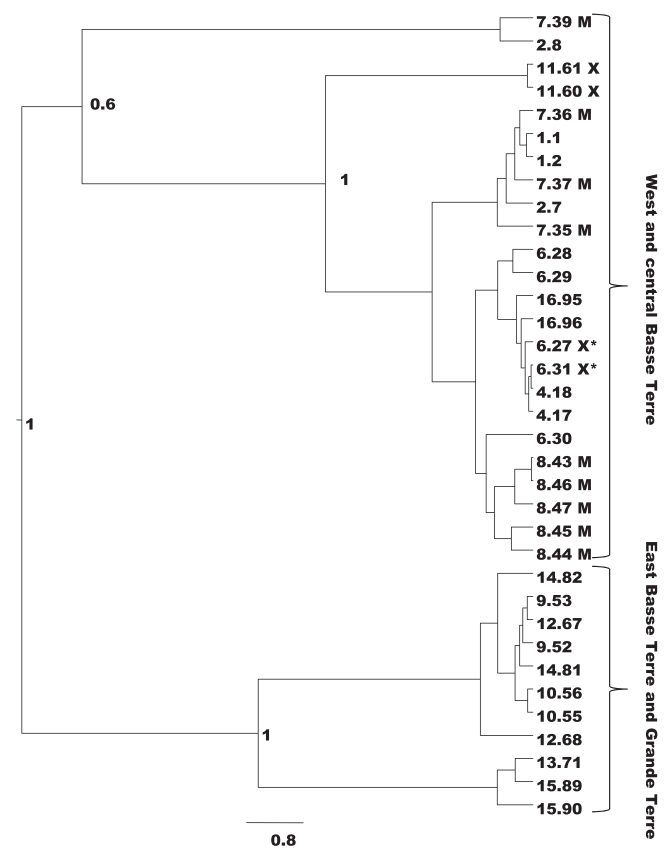

(C)

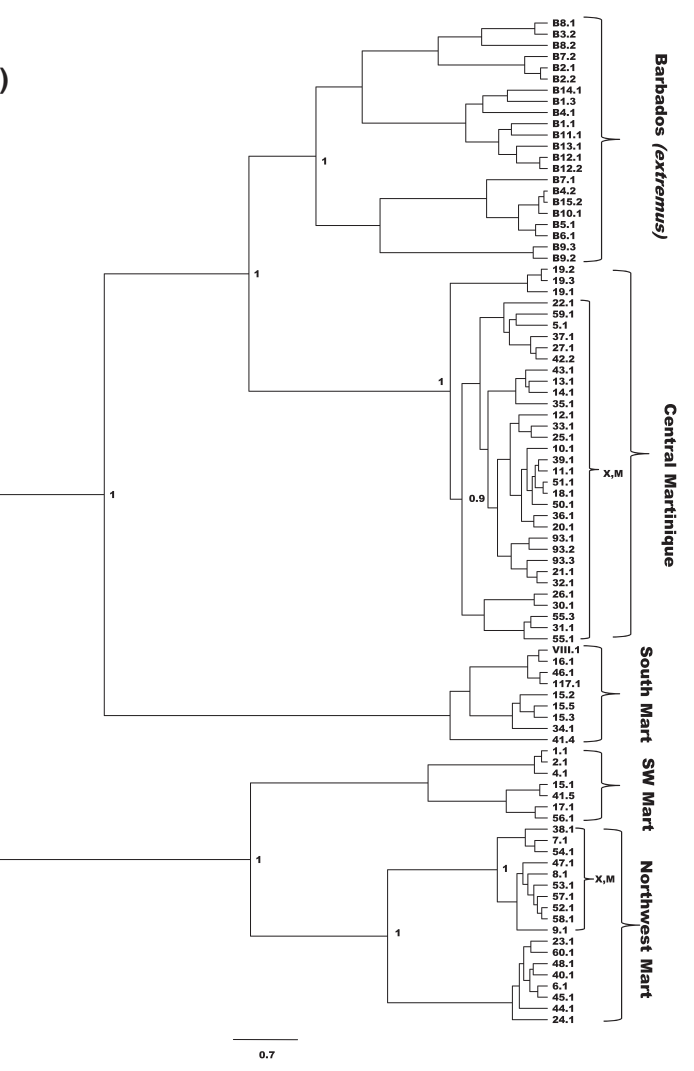

(B)

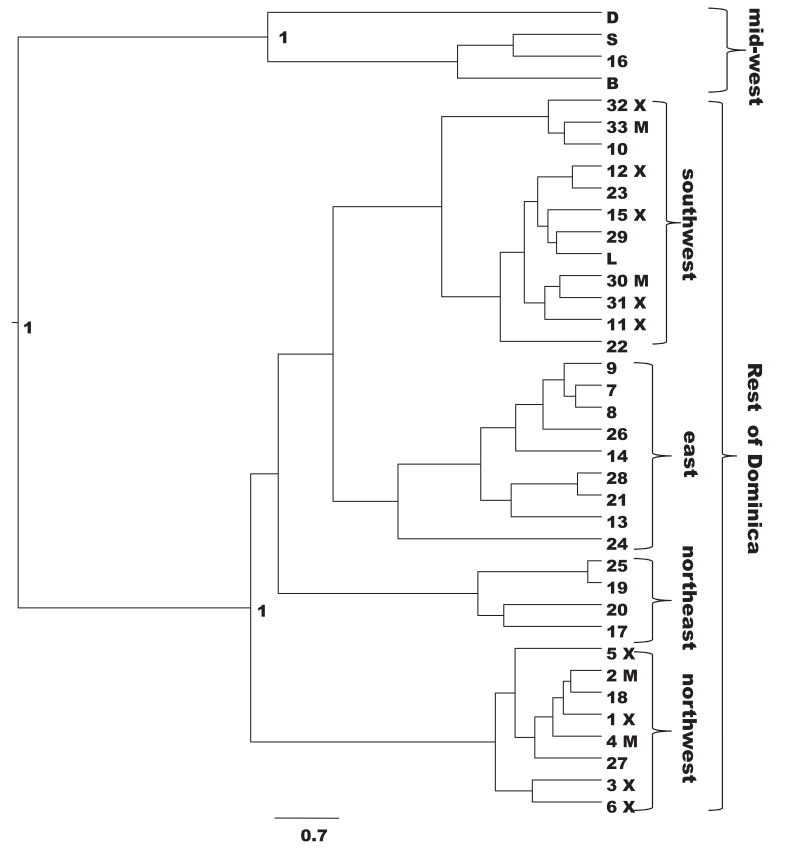

(D)

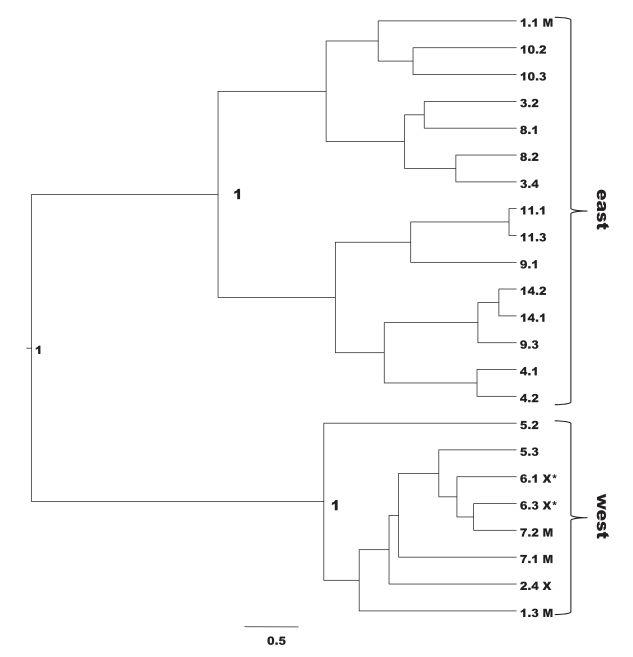

(E)

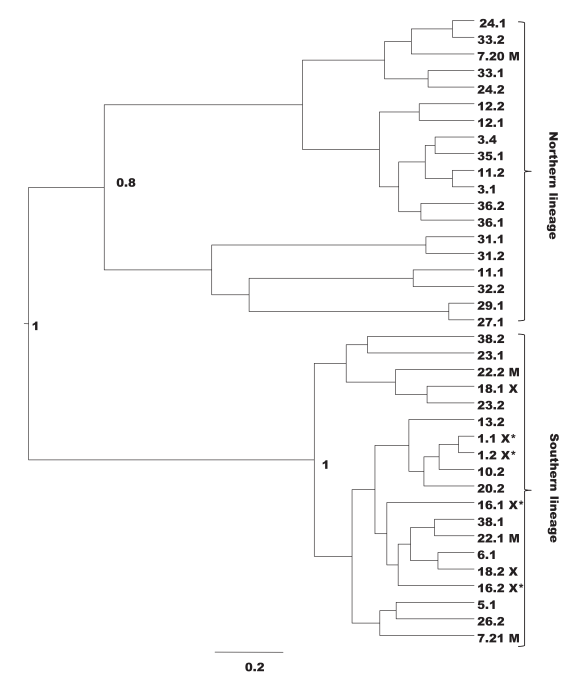


Fig. 3 Gene trees. Gene trees based on MT-CYB with site numbers in Fig. 1, unless otherwise stated. The deepest node, defining the primary lineages, is given posterior probabilities, and the terminal node number before the decimal point is the locality, and after the decimal point is the individual identifier. Individuals from studied xeric and montane sites are labelled $\mathrm{X}$ and $\mathrm{M}$ respectively. Scale bars indicate millions of years. See Fig. S1, Supporting information, for A. luciae and A. richardii. (A) Basse Terre. A. marmoratus. Only Basse Terre localities are included, not other islands/species in the marmoratus complex. East coast Basse Terre populations are more closely related to Grande Terre and other populations than they are to west Basse Terre populations (Stenson et al. 2004). Site 3 (xeric) is well within the range of the western phylogeographic lineage with site 6 (labelled $X^{*}$ ) being spatially closest. (B) Dominica A. oculatus. (C) Martinique A. roquet complex. The tree (Surget-Groba \& Thorpe 2013) includes A. extremus from Barbados (terminal node prefixed with B) as well as four historical allospecies (Thorpe et al. 2010). Allocation to a phylogeographic area in Fig. 1 is not based on these numbered sites (from Thorpe \& Stenson 2003; Thorpe et al. 2008), but on a more intensive study of the modal sequence deduced from PCR-RFLP analysis of 48 samples per transect site (Thorpe et al. 2010). The sublineages representing the phylogeographic areas these transect sites occupied are indicated ( $\mathrm{X}$ and $\mathrm{M}$ as above). (D) St Vincent, A. trinitatis. Xeric site 101 is well within the range of the western lineage with site 6 (labelled $X^{*}$ ) being spatially closest. (E) Grenada, A. aeneus. A tree based on MTCYB and MT-CO1. Site $1 \mathrm{~N}$ is well within the range of the southern lineage with sites 1 (labelled $\mathrm{X}^{*}$ ) and 16 spatially closest.

(NW2, 3, 6, 7). For A. roquet from Central Martinique, there are two xeric sites $(\mathrm{C} 3,4)$ and two montane sites $(C 1,2)$. These sites are selected on the basis of PCRRFLP analysis of modal lineage along densely sampled transects (48 samples per site) from Thorpe et al. (2010). Figure $3 \mathrm{c}$ indicates how these phylogeographic regions relate to the gene tree from Surget-Groba \& Thorpe (2013). The BEAST gene trees for A. luciae (Fig. S1a, Supporting Information) and A. richardii (Fig. S1c, Supporting information) are not well resolved, are incongruent to trees generated using alternative methods (Fig. S1b, $\mathrm{d}$, Supporting Information) and are not used to select sites. For A. richardii, two xeric and two montane sites are selected on the basis of climate from the southern section of Grenada and are the same as for its sympatric congener A. aeneus. For A. luciae, the sites are selected from the southern section of St Lucia on the basis of climate, that is, four xeric sites $(22,39,41,50)$ and five montane sites (32, 35, 42, 43, 47).

The species-by-species contrast AnOvas (Fig. 4, Table S1a, Supporting information) show that there are very pronounced differences between xeric and montane populations. These contrast analyses and tests for widespread parallel evolution (Fig. 4) indicate that all traits show some parallels, and half show widespread parallels across the radiations (Table 1). The extent of difference between the trait means for different habitats for a given species within an island can be very large considering their relative spatial proximity. For example (in units of within-site standard deviations), 5.2 for greenness, 4.8 for chromaticity, 6.2 chevron intensity, 2.0 lamellae number, 1.5 snout-vent length and 2.3 head length (Table S1, Supporting information). Traits from all systems, including all hues (red, green, blue, achromaticity), chevron pattern, dorsal scalation, head length, head width, toe length and dewlap size, show significant pervasive parallels, as do ventral scales for the roquet Series and snout-vent length for the bimaculatus Series (Table 1).

\section{Discussion}

The results provide overwhelming evidence for replicated, parallel morphological evolution in the Lesser Antillean anole radiations. Parallel morphological evolution in these lizards is largely independent of phylogeography, but rather appears to have been driven by differential natural selection resulting from the extreme, replicated pattern of climatic and habitat variation found on each island. Moreover, evidence that anoles have repeatedly overcome, and adapted to, the extreme climatic gradients presented by these mountainous islands has important implications for predicting how these species may respond to future, human-mediated climate change.

Most species show clear phylogeographic structure, which may relate closely in geography and timing to past geological events (Thorpe et al. 2010; Surget-Groba \& Thorpe 2013). Where the BEAST trees are well resolved, they show congruence to other tree reconstruction methods such as maximum parsimony, maximum likelihood and MRBAYES methods (Thorpe 2002; Thorpe \& Stenson 2003; Thorpe et al. 2008; Surget-Groba \& Thorpe 2013). Phylogeography tends to be independent of the largely altitudinal climatic zonation (Malhotra \& Thorpe 2000; Thorpe 2002; Thorpe \& Stenson 2003), so it has been possible to select xeric and montane habitat contrasts within a single well-resolved, primary phylogeographic area.

Parallel changes in hue are remarkably consistent and pronounced. In every species, the dorsal hue of xeric forms is more achromatic (greyish), while montane forms have a focal, more saturated, green coloration with a widespread reduction in blue, and frequent reduction in red, hues (Fig. S2, Supporting information). Colour pattern tends to be species-specific, but in species where chevrons occur, they are limited to xeric regions and xeric islands, including Blanquilla and xeric eastern islets and eastern Caravelle peninsula and some eastern islets on Martinique (Fig. 4, Fig. S2, Table S1a, 
Table 1 Pervasive parallel tests

\begin{tabular}{lcccc}
\hline Trait & $P$ & $F$ & d.f. 1,2 & No. species compared \\
\hline Red & $\mathrm{ns}$ & 2.4 & 1,37 & 8 \\
Green & $<0.001$ & 109.2 & 1,37 & 8 \\
Blue & $<0.001$ & 53.1 & 1,37 & 8 \\
Grey & $<0.001$ & 48.9 & 1,37 & 8 \\
Chevron & $<0.001$ & 85.1 & 1,11 & 4 \\
Ventral scales & $\mathrm{ns}$ & 2.0 & 1,37 & 7 \\
Dorsal scales & 0.013 & 8.4 & 1,12 & 8 \\
Circum-trunk scales & $\mathrm{ns}$ & 1.6 & 1,37 & 5 \\
Lamellae & $\mathrm{ns}$ & 3.2 & 1,31 & 8 \\
Snout-vent length & $\mathrm{ns}$ & 1.1 & 1,39 & 7 \\
Jaw length & $\mathrm{ns}$ & 3.7 & 1,37 & 7 \\
Head length & 0.001 & 12.0 & 1,37 & 7 \\
Head depth & $\mathrm{ns}$ & 2.5 & 1,37 & 8 \\
Head width & 0.005 & 9.1 & 1,39 & 7 \\
Upper leg length & $\mathrm{ns}$ & 0.7 & 1,37 & 8 \\
Lower leg length & $\mathrm{ns}$ & 0.1 & 1,39 & 8 \\
Toe length & 0.017 & 6.3 & 1,37 & 7 \\
Dewlap size & $<0.001$ & 19.7 & 1,35 & \\
\hline
\end{tabular}

Anoles across both Anolis bimaculatus and roquet. Series compared between habitats with a two-way ANova (habitat and species compared using male site means).

*Significant for roquet Series ( $F=5.7$, d.f. $1,24, P=0.026,6$ islands).

${ }^{\dagger}$ significant for bimaculatus Series ( $F=6.5$, d.f. 1,15, $P=0.023,2$ islands).

Supporting information). On Martinique, a range of colour pattern traits result in both montane and xeric habitat forms being remarkably similar within their own habitat type, irrespective of precursor island lineage (Fig. S2, Table S1d, Supporting information). Anoles are intermediate in the food chain, and their hue and pattern are a balance between crypsis to avoid predation and the need to be seen for intraspecific communication. While previous studies have not revealed this generalization regarding hue saturation in montane rainforests, a saturated green body may be cryptic against the frequent high (often green) chroma patches while the more variable light intensity may require a saturated colour for communication (Endler 1993). A more achromatic (warm-greyish) hue may be cryptic in the duller background of the open woodland of the xeric coast (aided by disruptive chevrons), and its less variable, brighter light environment may only require a less focal hue for communication. Similarly, the dappled black and white against a green dorsal background in montane Martinique anoles may be effective for crypsis in the montane rainforest with lush vegetation and dappled light. Experimental work with models may be effective at testing specific causal hypotheses as with lacertids (Husak et al. 2006) and rodents (Linnen et al. 2013).

Scalation also shows some widespread parallels. Ventral and dorsal scale numbers along the body tend to be higher in the montane forms of the roquet Series. The number of circum-trunk scales tends to be notably lower in the montane forms from northern islands (Basse Terre to Martinique), and the recently invasive A. cristatellus on Dominica shows a parallel trend developed in only a few years (Eales et al. 2010). It has been hypothesized (Soule \& Kerfoot 1972) that scale number should decrease with greater humidity and higher temperature as larger scales should be more sculptured with greater surface area. This hypothesis is problematic because (i) on these islands, temperature and humidity are inversely correlated, (ii) on some islands, different scale counts may appear to vary in opposing directions, (iii) and even with the same trait, the direction of change can differ between genera (Horton 1972), within genera (this study) and even within single-island species (compare circum-trunk scale variation in northern and southern Dominica, Table S1b, c, Supporting information). Nevertheless, the remarkably strong difference in circum-trunk scales between some xeric and montane populations, the multiple parallels (including A. cristatellus), the genetic control (Thorpe et al. 2005; Calsbeek et al. 2006; Eales et al. 2010), and the fact that natural selection experiments show they are significant targets of selection (Thorpe et al. 2005) argue that scalation is important in adapting the populations of many Lesser Antillean anole species to the xeric/montane contrast that they experience.

Body size and shape also show some widespread and pronounced differences between xeric and montane 

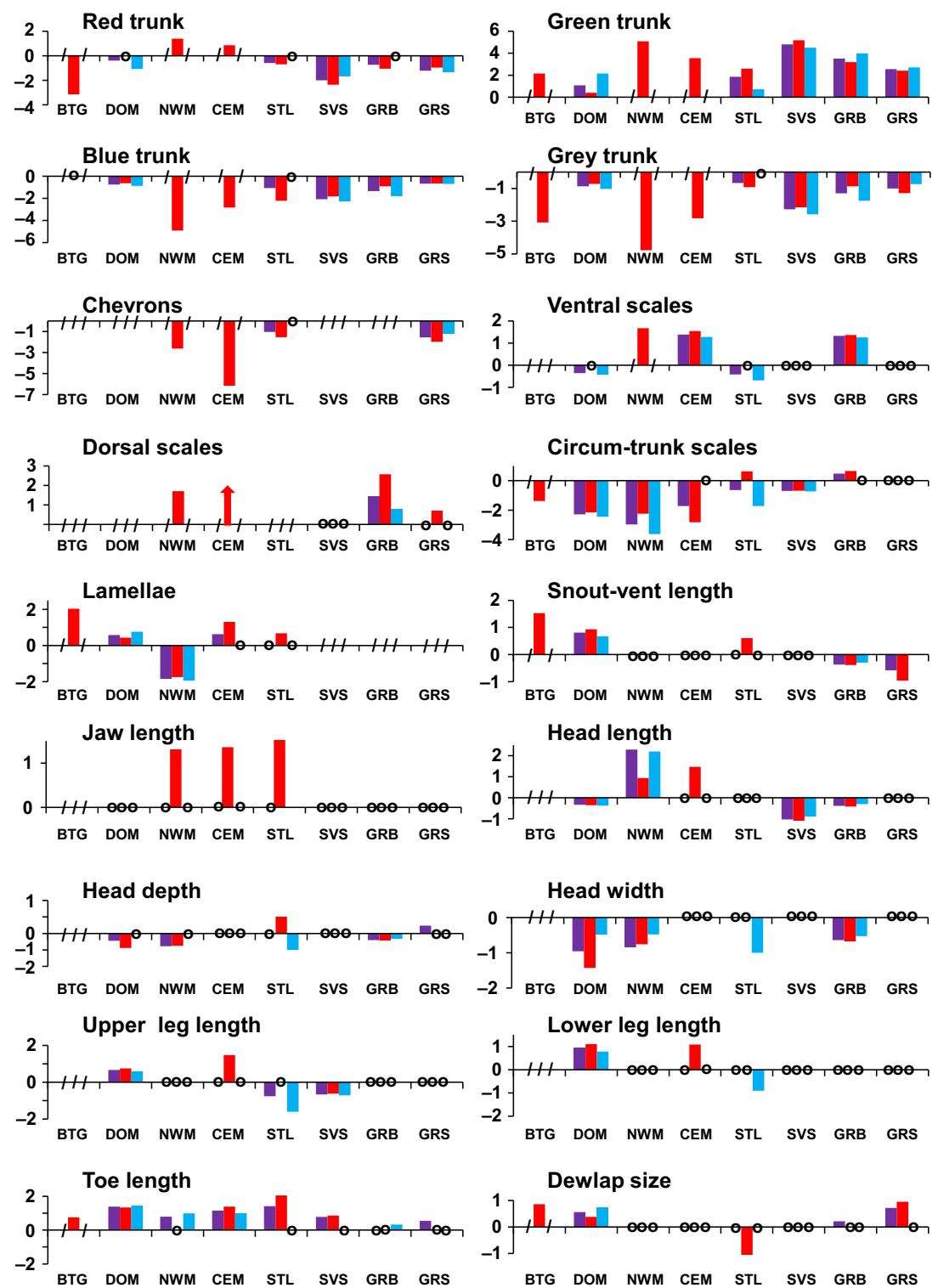

Fig. 4 Mean difference between montane rainforest and xeric contrast sets (montane-xeric) in units of pooled within-site standard deviation for quantitative traits. Purple is from a two-way contrast ANOVA using both sexes, while blue and red are from one way contrast ANOVAs of males and females, respectively (o $=P>0.05$, / = no comparison). Northern Anolis bimaculatus Series: BTG-Basse Terre, Guadeloupe (A. marmoratus), and DOMDominica (A. oculatus). Southern roquet Series: NWM-northwest Martinique (A. roquet); CEM-Central Martinique (A. roquet); STL-St Lucia (A. luciae); SVSSt Vincent (A. trinitatis); GRB-Grenada large species (A. richardii); and GRS-Grenada small species (A. aeneus). See Table S1a, Supporting information for statistics and details. forms. Montane anoles in the bimaculatus Series can be much larger (Table S1a, b, Supporting information). Size is heritable (Calsbeek \& Smith 2007; Losos 2009) and may impact many aspects of their biology, and there may be differences in resource (food and water) and predation between xeric and montane habitats. Nevertheless, there is no very convincing hypothesis as to why montane bimaculatus anoles should be larger. There is a widespread trend for montane forms to have longer toes (and more lamellae on some islands). Rainforest trees tend to be larger than xeric vegetation, and this is compatible with studies of Greater Antillean ecomorphs which suggests larger toepads on higher, wider trees for better locomotor performance and safety (Losos 2009). Montane forms tend to have narrower, and often shallower heads, although with some species, jaw length may be longer in montane forms. Jaw length and head shape may impact bite force, the ability to manoeuvre through dense vegetation (Losos 2009), be adapted to prey size or have a role in male-male agonism. Studies of Greater Antillean ecomorphs throw little light on this. With some exceptions, montane forms have relatively larger dewlaps. This may reflect the need for a larger dewlap in the lower light environment in the montane rainforest, but there is no experimental evidence for this.

During range expansion through the archipelago, the founder population on the xeric coast would have the capacity to increase its size rapidly and then rapidly expand their range into higher elevation areas in a few years. This has been directly witnessed by the recent colonization of south-west Dominica by A. cristatellus from 
Puerto Rico (Malhotra et al. 2007) in spite of congeneric competition from the endemic species in this case. The capacity for very rapid adaptation to these altitudinal climatic differences within Lesser Antillean islands is shown by translocation experiments on xeric and montane A. oculatus that showed significant coefficients of directional selection within 60 days (Malhotra \& Thorpe 1991) and the rapid adaptation of scalation characters during the range expansion into the higher elevations in Dominica of the invasive A. cristatellus (Eales et al. 2010). Moreover, other experiments on anoles have shown the capacity of anoles for rapid adaptation, for example the rapid evolution of Bahaman anoles due to the experimental introduction of predators (Calsbeek \& Smith 2003; Losos et al. 2004, 2006), the morphological differentiation in post-hurricane colonized islets (Calsbeek \& Smith 2003), the rapid natural selection response to experimental changes in population density (Calsbeek \& Cox 2010) and the rapid natural selection response of an endemic anole to the introduction of a competitive invasive species (Stuart et al. 2014).

It is apparent that species in the roquet and bimaculatus Series radiations can adapt to climate variation imposed by range expansion within each island, giving a novel example of remarkable universal or widespread parallel evolution across a broad spectrum of traits. This parallel evolution within-species provides strong evidence for natural selection (Arendt \& Reznick 2008; Wake et al. 2011) and a different, additional, case of deterministic evolution to that of interspecific ecomorphs found in the multispecies anole communities of the Greater Antilles (Losos 2009). The widespread parallel evolution in response to climate variation, and the capacity for rapid evolution in this group, has implications for the importance of climate change. This study suggests that anthropogenic climate change is less likely to be a conservation concern for anoles on the mountainous Lesser Antilles than other factors (May 2010) such as habitat destruction and invasive species, and that climate change may be met by adaptation by natural selection. A shift in the distribution to a higher elevation on these subconical islands, such as found in birds on Californian mountains (Tingley et al. 2009), would also ameliorate predicted anthropogenic climate. However, the occurrence of anoles in the most xeric Lesser Antillean habitats, and the occurrence of members of the roquet Series on the extremely xeric island of Bonaire (Fig. S2, Supporting Information), suggests this would not be necessary.

Mountainous oceanic island archipelagos, such as the Lesser Antilles, are frequently biodiversity hotspots (Myers et al. 2000). While these findings do not necessarily extrapolate to other taxa on this and other comparable archipelagos, the relative importance of the various factors impacting taxa in these biodiversity hotspots requires serious consideration. Small, mountainous, oceanic island are susceptible to factors such as habitat destruction and invasive species, and it may be that on these islands some taxa are much less vulnerable to climate change than these other factors.

\section{Acknowledgements}

We thank Mrinalini and Wendy Grail for help in the laboratory, Peter Wieland for early stage GIS work, Jacqueline Thorpe for assistance for fieldwork done under the Leverhulme Trust award, John Endler for discussions on colour of rainforest animals, and The Leverhulme Trust (RF/2/RFG/ 2010/0008) for funding to R.S.T.

\section{References}

Arendt J, Reznick D (2008) Convergence and parallelism reconsidered: what have we learned about the genetics of adaptation? Trends in Ecology and Evolution, 23, 26-32.

Barnosky AD, Matzke N, Tomiya S et al. (2011) Has the Earth's sixth mass extinction already arrived? Nature, 471, 51-57.

Bellard C, Bertelsmeier C, Leadley P, Thuiller P, Courchamp F (2012) Impacts of climate change on the future of biodiversity. Ecology Letters, 15, 365-377.

Brown RB, Thorpe RS, Baez M (1991) Parallel within-island microevolution of lizards on neighbouring islands. Nature, $352,60-62$.

Calsbeek R, Bonneaud C (2007) Variation in scale numbers is consistent with ecologically based natural selection acting within and between lizard species. Evolution, 62, 1137-1148.

Calsbeek R, Cox RM (2010) Experimentally assessing the relative importance of predation and competition as agents of selection. Nature, 465, 613-616.

Calsbeek R, Smith TB (2003) Ocean currents mediate evolution in island lizards. Nature, 426, 552-555.

Calsbeek R, Smith TB (2007) Probing the adaptive landscape using experimental islands: density-dependent natural selection on lizard body size. Evolution, 61, 1052-1061.

Calsbeek R, Knouft JH, Smith TB (2006) Variation in scale number is consistent with ecologically based natural selection acting within and between lizard species. Evolutionary Ecology, 20, 377-394.

Colosimo PF, Hosemann KE, Balabhadra S et al. (2005) Widespread parallel evolution in sticklebacks by repeated fixation of ectodysplasin alleles. Science, 307, 1928-1933.

Drummond AJ, Suchard MA, Xie D, Rambaut A (2012) Bayesian phylogenetics with BEAUTI and the BEAST 1.7. Molecular Biology and Evolution, 29, 1969-1973.

Eales J, Thorpe RS, Malhotra A (2010) Colonisation history and genetic diversity: adaptive potential in early stage invasions. Molecular Ecology, 19, 2858-2869.

Endler JA (1993) The color of light in forests and its implications. Ecological Monographs, 63, 1-27.

Folmer O, Black M, Hoeh W, Lutz R, Vrijenhoek R (1994) DNA primers for amplification of mitochondrial cytochrome c oxidase subunit I from diverse metazoan invertebrates. Molecular Marine Biology and Biotechnology, 3, 294-299. 
Guindon S, Gascuel O (2003) A simple, fast and accurate method to estimate large phylogenies by maximum-likelihood. Systematic Biology, 52, 696-704.

Horton DR (1972) Lizard scale size and adaptation. Systematic Zoology, 21, 441-443.

Husak JF, Macedonia JM, Fox S, Sauceda RC (2006) Predation cost of conspicuous male coloration in collared lizards (Crotaphytus collaris): an experimental test using clay-covered model lizards. Ethology, 112, 572-580.

Kolbe JJ, Losos JB (2005) Hind-limb length plasticity in Anolis carolinensis. Journal of Herpetology, 39, 674-678.

Linnen CR, Poh Y-P, Peterson BK et al. (2013) Adaptive evolution of multiple traits through multiple mutations at a single gene. Science, 339, 1312-1316.

Losos JB (2009) Lizards in an Evolutionary Tree. University of California Press, Berkeley, California.

Losos JB, Schoener TW, Spiller DA (2004) Predator-induced behaviour shifts and natural selection in field-experimental lizard populations. Nature, 432, 505-508.

Losos JB, Schoener TW, Langerhans RB, Spiller DA (2006) Rapid temporal reversal in predator-driven natural selection. Science, 314, 1111.

Mahler DL, Ingram T, Revell LJ, Losos JB (2013) Exceptional convergence on the macroevolutionary landscape in island lizard radiations. Science, 341, 292-295.

Malhotra A, Thorpe RS (1991) Experimental detection of rapid evolutionary response in natural lizard populations. Nature, 353, 347-348.

Malhotra A, Thorpe RS (2000) The dynamics of natural selection and vicariance in the Dominican anole: patterns of within-island molecular and morphological divergence. Evolution, 54, 245-258.

Malhotra A, Thorpe RS, Hypolite E, James A (2007) A report on the status of the herpetofauna of the Commonwealth of Dominica, West Indies. Applied Herpetology, 4, 177-194.

Martin-Kaye PHA (1969) A summary of the geology of the Lesser Antilles. Overseas Geology and Mineral Research Journal, 10, 172-206.

May RM (2010) Ecological science and tomorrow's world. Philosophical Transactions of the Royal Society Series B: Biological Sciences, 365, 41-47.

Myers N, Mittermeier RA, Mittermeier CG, da Fonseca GAB, Kent J (2000) Biodiversity hotspots for conservation priorities. Nature, 403, 853-858.

Nakicenovic N, Swart R (2000) IPCC Special Report on Emissions Scenarios, Cambridge University Press, Cambridge, UK.

Nosil P, Crespi BJ, Sandoval CP (2002) Host-plant adaptation drives the parallel evolution of reproductive isolation. Nature, 417, 440-443.

Pespeni MH, Sanford E, Gaylord B et al. (2013) Evolutionary change during experimental ocean acidification. Proceedings of the National Academy of Sciences, USA, 110, 6937-6942.

Posada D (2008) jModelTest: phylogenetic model averaging. Molecular Biology and Evolution, 25, 1253-1256.

Quintero I, Wiens JJ (2012) Impacts of climate change on the future of biodiversity. Ecology Letters, 15, 365-377.

Ronquist F, Huelsenbeck JP (2003) MRBAYES 3: Bayesian phylogenetic inference under mixed models. Bioinformatics, 19, 1572-1574.

Schat H, Voous R, Kuiper E (1996) Identical major gene loci for heavy metal tolerances that have independently evolved in different local populations and subspecies of Silene vulagaris. Evolution, 50, 1888-1895.

Seltman HJ (2014) Experimental design and analysis. Available at: http://www.stat.cmu.edu/ hseltman/309/Book/ Book.pdf.

Solomon S, Qin D, Manning M et al. (eds) (2007) IPCC Climate Change 2007: the physical science basis. Contribution of Working Group I to the Fourth Assessment Report of the Intergovernmental Panel on Climate Change. 996 pp. Cambridge University Press, Cambridge, UK and New York, NY, USA

Soule M, Kerfoot WC (1972) On the climatic determination of scale size in a lizard. Systematic Zoology, 21, 97-105.

Stenson AG, Malhotra A, Thorpe RS (2002) Population differentiation and nuclear gene flow in the Dominican anole ( $A n-$ olis oculatus). Molecular Ecology, 11, 1679-1688.

Stenson AG, Thorpe RS, Malhotra A (2004) Evolutionary differentiation of bimaculatus group anoles based on analyses of mtDNA and microsatellite data. Molecular Phylogeny and Evolution, 32, 1-10.

Stuart YE, Campbell TS, Hohenlohe PA, Revell LJ, Losos JB (2014) Rapid evolution of a native species following invasion by a congener. Science, 346, 463-466.

Surget-Groba Y, Thorpe RS (2013) A likelihood framework analysis of an island radiation: phylogeography of the Lesser Antillean gecko Sphaerodactylus vincenti, in comparison with the anole Anolis roquet. Journal of Biogeography, 40, 105-116.

Surget-Groba Y, Johansson H, Thorpe RS (2012) Synergy between allopatry and ecology in population differentiation and speciation. International Journal of Ecology, 2012, Article ID 273413, 10 pages.

Thorpe RS (1988) Multiple group principal component analysis and population differentiation. Journal of Zoology, London, 216, 37-40.

Thorpe RS (2002) Analysis of color spectra in comparative evolutionary studies: molecular phylogeny and habitat adaptation in the St. Vincent anole (Anolis trinitatis). Systematic Biology, 51, 554-569.

Thorpe RS, Stenson AG (2003) Phylogeny, paraphyly and ecological adaptation of the colour and pattern in the Anolis roquet complex on Martinique. Molecular Ecology, 12, 117132.

Thorpe RS, Reardon JT, Malhotra A (2005) Common garden and natural selection experiments support ecotypic differentiation in the Dominican anole (Anolis oculatus). American Naturalist, 165, 495-504.

Thorpe RS, Surget-Groba Y, Johansson H (2008) The relative importance of ecology and geographic isolation for speciation in anoles. Philosophical Transactions of the Royal Society Series B: Biological Sciences, 363, 3071-3081.

Thorpe RS, Surget-Groba Y, Johansson H (2010) Genetic tests for ecological and allopatric speciation in anoles on an island Archipelago. Public Library of Science, Genetics, 6, e1000929.

Thorpe RS, Surget-Groba Y, Johansson H (2012) Quantitative traits and mode of speciation in Martinique anoles. Molecular Ecology, 21, 5299-5308.

Tingley MW, Monahan WB, Beissinger SR, Moritz C (2009) Birds track their 283 Grinnellian niche through a century of climate change. Proceedings of the National Academy of Sciences, USA, 106, 19637-19643. 
Wake DB, Wake MH, Specht CD (2011) Homoplasy: from detecting pattern to determining process and mechanism of evolution. Science, 331, 1032-1035.

Wood TE, Burke JM, Rieseberg LH (2005) Parallel genotypic adaptation: when evolution repeats itself. Genetica, 123, 157170

R.S.T. designed the study, recorded Q.T. data from southern islands, analysed the Q.T. data and wrote the first draft, A.B. performed phylogenetic analyses and supplementary sequencing, Y.S.G. recorded Q.T. data from Martinique and performed sequencing for the roquet Series, A.M. recorded Q.T. data and performed sequencing for the bimaculatus Series. All authors contributed to writing the manuscript.

\section{Data accessibility}

DNA sequences are held in GenBank (AF493583AF493603, KP676987-KP677274). Site coordinates, quan- titative trait data, climate data, both principal component outputs, phylogenetic data in nexus format and phylogenetic trees generated in this study are in the Dryad Data Repository doi:10.5061/dryad.r8tp2.

\section{Supporting information}

Additional supporting information may be found in the online version of this article.

Appendix S1 Data sets and additional methods.

Fig. S1 Gene trees for A. luciae and A. richardii.

Fig. S2 Images of male and female anoles from xeric and montane rainforest habitat for each island species.

Table S1 Mean difference between xeric and montane rainforest contrast sets in units of pooled within-site standard deviation and associated statistics.

Table S2 Data for male site means on which Table 1 is based. 